Jurnal Geografi, Edukasi dan Lingkungan (JGEL) Vol. 4, No. 1, Januari 2020:39-49

P-ISSN: 2579-8499; E-ISSN: 2579-8510

Doi: https://doi.org/10.29405/jgel.v4i1.4315

Website: http://journal.uhamka.ac.id/index.php/jgel

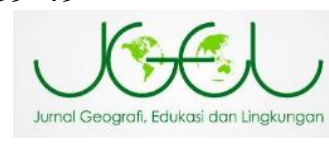

\title{
Respon Mitigasi Bencana Gempa Bumi Di SMP M 7 Bayat Dan SMP MBS 2 Prambanan
}

\author{
Tomi Kurniawan Pratama*, Ruli Ratna Sarir, Nurul Zakhra Utami, Ana Zairotul \\ Mufidah, Lintang Setyadi, dan Puspita Indra Wardani \\ Program Studi Pendidikan Geografi, FKIP Universitas Muhammdiyah Surakarta, \\ Surakarta, Jawa Tengah, Indonesia
}

*E-mail: imotkurniawan453@gmail.com

Received: 18012020 / Accepted: 20012020 / Published online: 30012020

\begin{abstract}
ABSTRAK
Kabupaten Klaten menjadi salah satu kabupaten di provinsi Jawa Tengah yang terdampak gempa tahun 2006. Pada 27 Mei 2006, Kabupaten Klaten dilanda bencana gempa bumi dengan kekuatan 6,3 Skala Richter yang mengakibatkan banyaknya bangunan rusak dan korban jiwa. Sekolah yang merasakan dampak langsung dari gempa 27 Mei 2006 yaitu SMP Muhammadiyah 7 Bayat dan SMP MBS 2 Prambanan. Tujuan dari penelitian ini adalah untuk mengetahui tingkat pengetahuan dan respon warga SMP Muhammadiyah 7 Bayat dan SMP MBS 2 Prambanan terhadap bencana gempa bumi. Jenis penelitian yang digunakan dalam penelitian ini adalah kuantitatif deskriptif. Populasi dalam penelitian ini adalah seluruh warga sekolah SMP Muhammadiyah 7 Bayat dan SMP MBS 2 Prambanan. Sampel diambil secara acak terhadap data siswa dari masing-masing sekolah. Jumlah sampel ditentukan dengan menggunakan rumus Slovin dengan taraf kepercayaan 95\% dan diperoleh jumlah sampel sebanyak 202 sampel penelitian. Teknik pengambilan data dalam penelitian ini menggunakan kuisioner, wawancara, observasi, dan dokumentasi. Hasil penelitian menunjukkan bahwa SMP Muhammadiyah 7 Bayat memiliki tingkat pengetahuan dan respon yang rendah dikarenakan kurangnya sosialisasi dan simulasi tentang kebencanaan, sedangkan SMP MBS 2 Prambanan memiliki tingkat pengetahuan dan respon yang tinggi terhadap bencana. Hal ini merupakan hasil penerapan kurikululum bencana dan sosialisasi kebencanaan secara berkala. Berdasarkan hasil penelitian faktor-faktor yang mempengaruhi tingkat respon siswa terhadap bencana gempa bumi adalah pengalaman siswa tentang bencana, pengetahuan siswa tentang bencana, tingkat kesiapsiagaan siswa, pemahaman siswa tentang mitigasi bencana, respon siswa terhadap gempa bumi dan respon siswa terhadap bencana.
\end{abstract}

Kata Kunci: Mitigasi Bencana, Gempa Bumi, dan Respon Siswa

\section{ABSTRACT}

Klaten Regency became one of the districts in Central Java that was affected by the 2006 earthquake. On May 27, 2006, Klaten was hit by an earthquake with a magnitude 6.3 on the Scale of MMI, which tragically damaged many buildings and fatalities. One of school that felt the impact of May 27, 2006 earthquake were Junior High School Muhammadiyah 7 Bayat and Junior High School Prambanan 2. The aim of this study was to determine the level of knowledge and response of all 
the school community of SMP Muhammadiyah 7 Bayat and SMP MBS 2 Prambanan to the earthquake disaster. This research is descriptive quantitative research. The population in this study were all the school community of SMP Muhammadiyah 7 Bayat and SMP MBS 2 Prambanan. The samples were taken randomly from student data each school. The number of samples was determined using the Slovin formula with a confidence level of $95 \%$ and obtained a total sample of 202 research samples. Data collection techniques in this study used questionnaires, interviews, observations, and documentation. The results show that Junior High School of Muhammadiyah 7 Bayat has a low level of knowledge and response due to lack of socialization and simulation about disasters, while Junior High School of MBS 2 Prambanan has a high level of knowledge and response to disasters, this is the result of the disaster curriculums and periodic socialization of disasters that have been applicated in this school. Based on the results of the research, the factors that influence the level of student response to earthquake disasters are student experience about disasters, student knowledge about disasters level of student preparedness, student understanding of disaster mitigation, student responses to earthquakes and student responses to disasters.

Keywords: Disaster Mitigation, earthquake, Student Response

\section{PENDAHULUAN}

Pada tahun 2006 di wilayah Yogyakarta dan Jawa Tengah terjadi bencana alam yang menimbulkan banyak korban jiwa dan kehilangan harta benda. Bencana alam berupa gempa bumi yang dipicu oleh sesar aktif opak. Gempa bumi adalah getaran atau guncangan yang terjadi dan dirasakan di permukaan bumi yang berasal dari dalam struktur bumi. Referensi gempanya ditambah karena faktor yang memicu gempa bermacammacam (Christanto, 2011).

Kabupaten Klaten menjadi salah satu kabupaten di provinsi Jawa Tengah yang terdampak gempa tahun 2006. Pada 27 Mei 2006, Klaten dilanda bencana gempa bumi dengan kekuatan 6,3 Skala Richter yang mengakibatkan banyaknya bangunan rusak dan korban jiwa. Wilayah Kabupaten Klaten yang merasakan dampak dari gempa 2006 yaitu Prambanan, Gantiwarno, Wedi, dan Bayat. Gempa ini merusak beberapa fasilitas umum seperti puskesmas, tempat ibadah, kantor desa, layanan kesehatan dan sekolah (BPBD, 2014). Sekolah yang merasakan dampak langsung dari gempa 27 Mei 2006 yaitu SMP Muhammadiyah 7 Bayat dan SMP MBS 2 Prambanan. Kerusakan yang diakibatkan dari gempa ini seperti bangunan retak, kaca pecah, atap genting yang jatuh. Dalam insiden ini tidak adanya korban jiwa karena kejadian saat gempa berlangsung sebelum dimulainya kegiatan KBM tepatnya jam 05:55 WIB .

Respon terhadap bencana merupakan suatu kegiatan atau aktivitas dari seorang individu dalam menanggapi suatu gejala bencana dimana respon ditimbulkan oleh suatu rangsangan dan terjadi secara sadar. Secara umum respon atau tanggapan dapat diartikan sebagai hasil atau kesan yang didapat dari pengamatan tentang subjek, peristiwa atau hubunganhubungan yang diperoleh dengan menyimpulkan informasi dan menafsirkan gejala yang terjadi. 
Respon terhadap bencana dianggap perlu dimiliki oleh setiap individu dikarenakan respon terhadap bencana merupakan salah satu upaya bermitigasi bencana dalam situasi prabencana, saat terjadi bencana dan paska bencana, sekaligus menjadi indikator seorang individu memiliki kapasitas yang cikup dalam bermitigasi bencana. Respon terhadap suatu bencana menjadi indikator tingkat kapasitas suatu wilayah yang meliputi kesiapsiagaan terhadap bencana, persepsi tiap individu terhadap bencana, pengetahuan terhadap bencana dari gejala hingga cara bermitigasinya, hal ini menjadikan respon terhadap bencana memiliki manfaat jangka panjang melihat bencana dapat terjadi kapanpun, dimanapun tanpa direncanakan (Pasau \& Guntur 2011).

Hal yang mempengaruhi respon terhadap bencana adalah sikap, pengetahuan dan partisipasi (Kusuma 2017). Respon mitigasi harus berkelanjutan sehingga mencegah timbulnya rasa apatis warga sekolah selama waktu yang panjang, tetang bagaimana tanggapan mereka terhadap kejadian gempa bumi yang pernah mereka hadapi, agar kedepannya mereka lebih siap dalam menghadapi bencana. Berdasarkan hal itu, tujuan dari penelitian ini adalah untuk mengetahui tingkat pengetahuan dan respon warga SMP Muhammadiyah 7 Bayat dan SMP MBS 2 Prambanan terhadap bencana gempa bumi.

\section{METODE PENELITIAN}

\section{Waktu dan Lokasi Penelitian}

Penelitian ini dilaksanakan di sekolah tingkat SMP sederajat di Kabupaten Klaten terkhusus sekolah berbasis Muhammadyah, dalam penelitian ini sekolah yang dijadikan objek penelitian adalah SMP
Muhammadiyah 7 Bayat dan SMP MBS Prambanan (Gambar 1) yang dilaksanakan tanggal 3 sampai 6 November 2019. Kegiatan penelitian ini meliputi tahapan persiapan, survey lokasi penelitian, pengumpulan data, analisis data dan pembuatan peta serta pembuatan laporan.

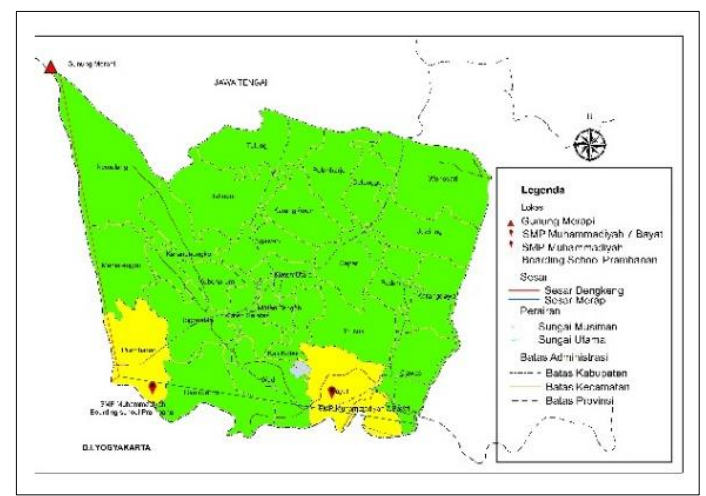

Gambar 1: Peta Lokasi Wilayah Penelitian

\section{Jenis Penelitian}

Pendekatan yang digunakan pada penelitian ini yaitu menggunakan pendekatan deskriptif dengan menguraikan bencana gempa bumi dan respon warga sekolah terhadap bencana gempa bumi. Cakupan penelitiannya mengarah pada tingkat respon warga sekolah terhadap adanya bencana gempa bumi. Jenis metode penelitian yang dipilih adalah deskriptif analisis, adapun pengertian dari metode deskriptif analisis menurut (Sugiono, 2009) adalah suatu metode yang berfungsi untuk mendeskripsikan atau memberi gambaran terhadap objek yang diteliti melalui data atau sampel yang telah terkumpul sebagaimana adanya tanpa melakukan analisis dan membuat kesimpulan yang berlaku untuk umum.

Metode pengumpulan, pengolahan, dan Analisis Data

Jenis penelitian yang digunakan dalam penelitian ini adalah metode deskriptif kuantitatif. Penelitian 
deskriptif kuantiatif adalah penelitian yang berlandaskan pada filsafat positivisme, digunakan untuk meneliti pada populasi atau sampel tertentu, pengumpulan data menggunakan instrumen penelitian, analisis data bersifat kuantitatif atau statistik yang sederhana (Siregar, 2013). Penelitian deskriptif kuantitatif ini dimaksudkan untuk mendapatkan suatu data mengenai tingkat respon siswa terhadap bencana gempa bumi.

Jenis-jenis data yang digunakan dalam penelitian adalah data primer dan data sekunder. Data primer merupakan data yang diambil langsung pada sumbernya seperti pada saat observasi di lapangan. Data sekunder merupakan data-data pendukung seperti buku, jurnal, artikel, Citra Google Earth peta adminitrasi Kabupaten Klaten (Gambar 2) yang diperoleh dari peta RBI skala 1:175.000. Teknik pengumpulan data yang digunakan penelitian ini adalah teknik observasi, wawancara, dokumentasi. Wawancara yang dilakukan dengan cara menggunakan instrumen yang berupa kuesioner serta menganalisis pendapat dari subyek penelitian.

Jenis analisis data yang digunakan dalam penelitian ini adalah analisis data secara deskriptif. Analisis data secara deskriptif adalah teknik analisis yang digunakan dalam menganalisis data dengan cara membuat gambaran-gambaran data yang terkumpul tanpa membuat generalisasi dari hasil penelitian tersebut. Hasil dari data penelitian yang berasal dari data wawancara dan kuesioner yang dilakukan pada siswa dihitung hasil data tersebut dengan koding Microsoft Excel kemudian diuraikan dalam bentuk tabel, grafik, sehingga diperoleh kesimpulan dari data tersebut. Analisis data tersebut dapat digunakan untuk mendekripsikan tingkat respon siswa terhadap bencana gempa bumi.

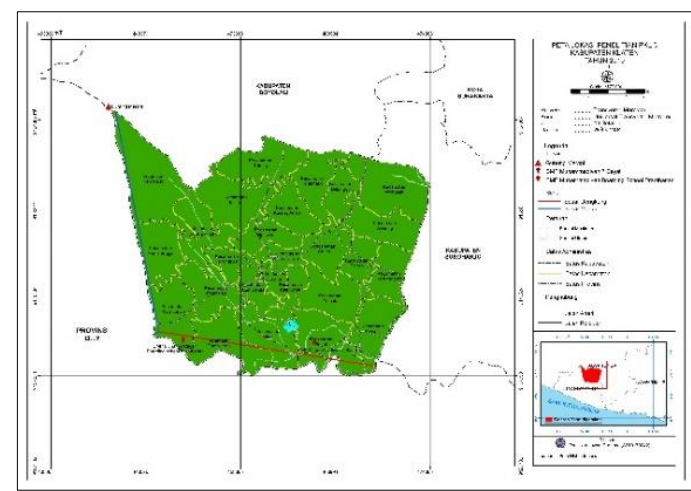

Gambar 2: Peta Administrasi Kabupaten Klaten 2019

HASIL DAN PEMBAHASAN Pengalaman siswa tentang bencana

Salah satu yang dapat mempengaruhi kesiapsiagaan individu adalah dengan adanya pengalaman bencana di masa lalu baik yang dialami secara langsung maupun secara tidak langsung. Menurut Chairummi (2013), menyatakan bahwa "kesiapsiagaan terhadap bencana yang belum baik karena pengalaman mengenai bencana yang belum pernah dialami, dan salah satu faktor yang mempengaruhi perilaku kesiapsiagaan adalah pengalaman bencana". Menurut Syuaib (2013) menyatakan bahwa "Pengalaman pribadi yang telah dan sedang dialami akan ikut membentuk dan mempengaruhi penghayatan siswa terhadap stimulus lingkungan sosial misalnya, peristiwa bencana alam, respon yang terjadi pada dirinya menjadi salah-satu dasar terbentuknya sikap untuk dapat mempunyai tanggapan, dan penghayatan seseorang yang mempunyai pengalaman berkaitan dengan bencana alam atau objek psikologis". Pengalaman siswa tentang bencana khusunya di SMP 7 Bayat dan MBS Prambanan dalam menghadapi ancaman gempa bumi di 
daerah Kabupaten Klaten disajikan pada Gambar 3 dan 4.

Pengalaman Siswa Tentang Bencana Di SMP Muhammadiyah 7 Bayat

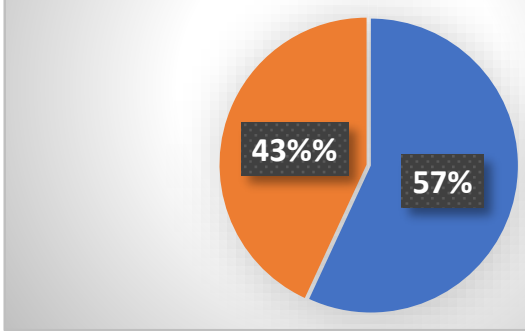

Gambar 3: Grafik Pengalaman Siswa SMP Muhammadiyah 7 Bayat Tentang Bencana

Pengalaman Siswa Tentang Bencana Di MBS Prambanan

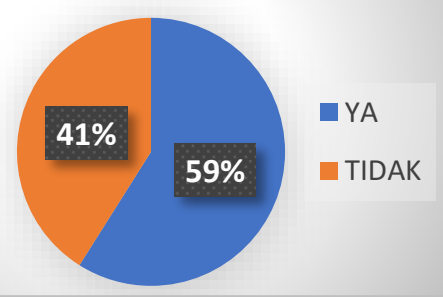

Gambar 4: Grafik Pengalaman Siswa SMP MBS Prambanan Tentang Bencana

Berdasarkan Gambar 3 tingkat pengalaman siswa di SMP Muhammadiyah 7 Bayat dan MBS Prambanan, menunjukkan bahwa SMP Muhammadiyah 7 Bayat memiliki presentasi $57 \%$ berpengalaman terhadap bencana. Siswa dengan pengalaman bencana yang kurang tercatat $43 \%$. Hal ini dipengaruhi dari rentan usia yang jauh dari terjadinya bencanan gempa sehingga pengalaman secara langsung terhadap bencana masih kurang (Kartika 2008). Berdasarkan hal tersebut, untuk SMP Muhammadiyah 7 Bayat sudah memiliki tingkat pengalaman bencana yang baik

Berbeda dengan diagram pengalaman siswa di MBS Prambanan (Gambar 4) yang memiliki presentasi siswa pengalaman bencana sebesar $59 \%$, hal ini dikarenakan populasi siswa yang multikultural berasal dari berbagai daerah seluruh Indonesia, sehingga pengalaman tentang bencana di Indonesia lebih tinggi. Persentase siswa dengan belum berpengalam terhadap bencana yaitu $41 \%$, salah satu faktor penyebabnya adalah rentan usia yang jauh dari terjadinya bencanan gempa sehingga pengalaman secara langsung terhadap bencana masih kurang. Hal ini memiliki kesamaan dengan kendala di SMP Muhammadiyah 7 Bayat. Dapat disimpulkan untuk MBS Prambanan sudah memiliki tingkat pengalaman bencana yang lebih tinggi.

Pengalaman bencana akan menjadi suatu pembelajaran yang berguna dimasa yang akan datang. Hal ini terlihat ketika terjadi bencana, maka individu yang mengalami tentu saja memiliki trauma tersendiri. Trauma yang dialami akan memberikan sebuah respon dan pembelajaran untuk menjadikannya sebagai suatu informasi (Jufriadi 2012). Informasi yang diperoleh akan menghasilkan suatu tindakan apa yang harus dilakukan ketika bencana tersebut terulang kembali.

\section{Pengetahuan Siswa Tentang Bencana}

Pengetahuan siswa terhadap bencana sangatlah penting guna mengurangi tingkat kerentanan terhadap bencana dan menambah kapasitas pengetahuan bencana Pengetahuan siswa tentang bencana di SMP 7 Bayat dan MBS Prambanan tentang bencana siswa dalam menghadapi ancaman gempa bumi di daerah Kabupaten Klaten disajikan pada Gambar 5 dan 6. 
Pengetahuan Siswa Tentang Bencana Di SMP Muhammadiah 7 Bayat

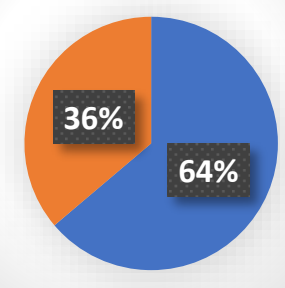

Gambar 5: Grafik Pengetahuan Siswa SMP Muhammadiyah 7 Bayat Tentang Bencana

Pengetahuan Siswa Tentang Bencana Di MBS Prambanan

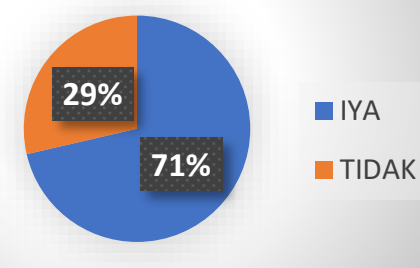

Gambar 6: Grafik Pengetahuan Siswa SMP MBS Prambanan Tentang Bencana

Berdasarkan Gambar 5, siswa SMP Muhammadyah 7 Bayat siswa memiliki pengetahuan tentang bencana sebesar $64 \%$. Hal ini merupakan hasil dari adanya sosialisasi kebencanaan pada tiap mata pelajaran terkait seperti IPS terpadu, sehingga secara tidak langsung siswa mampu memahami tentang apa itu bencana secara teori. Selain itu, tercatat $36 \%$ siswa belum mengetahui dengan benar tentang apa itu bencana.

Pengetahuan bencana siswa SMP MBS Prambanan memiliki hasil $71 \%$ siswa paham terkait pengetahuan tentang bencana. Hal ini dikarenakan MBS Prambanan merupakan salah satu sekolah yang dijadikan objek penelitian tentang kebencanaan dan sering adanya sosialisai kebencanaan dari instansi terkait, sehingga tingkat pemahaman siswa tentang bencana sangatlah tinggi. Persentase siswa yang memiliki tingkat pemahaman kurang tentang bencana yaitu 29\%, data tersebut dapat di simpulkan siswa MBS Prambanan sudah memiliki kapasitas pengetahuan bencana yang tinggi.

\section{Tingkat Kesiapsiagaan Siswa}

Tingkat kesiapsiagaan siswa merupakan langkah awal dalam menghadapi bencana, hal ini merupakan persiapan pra bencana pada siswa guna mengurangi risiko bencana (Ardiansyah 2017). Tingkat kesiapsiagaan siswa di SMP 7 Bayat dan SMP MBS Prambanan dalam menghadapi ancaman gempa bumi di daerah Kabupaten Klaten disajikan pada Gambar 7 dan 8.

Tingkat Kesiapsiagaan Siswa Di SMP Muhammadiyah 7 Bayat

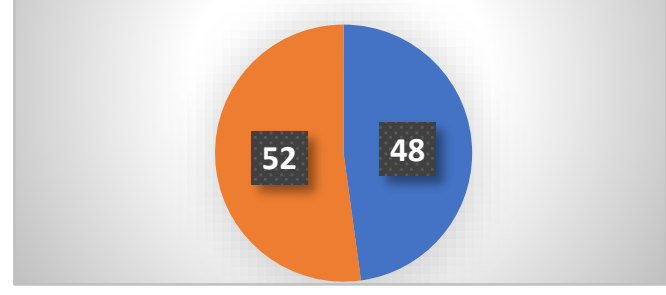

Gambar 7: Grafik Kesiapsiagaan siswa SMP Muhammadiyah 7 Bayat

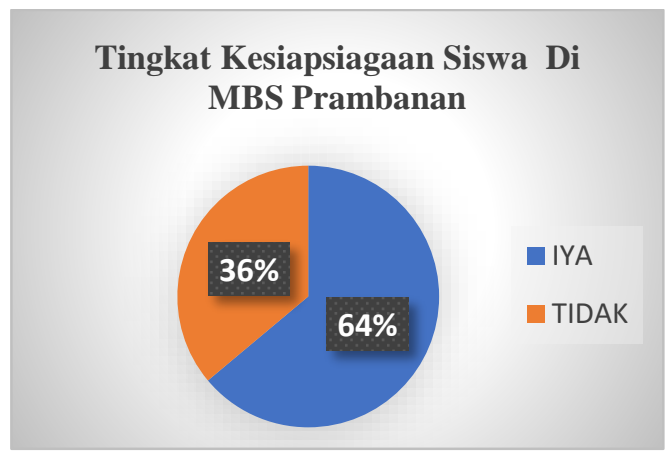

Gambar 8: Grafik Kesiapsiagaan siswa SMP MBS Prambanan

Grafik tingkat kesiapsiagaan SMP Muhammadiyah 7 Bayat (Gambar 7), tercatat memiliki tingkat kesiapsiagaan sebesar 48\%. Hal ini menandakan kurangnya sosialisasi dan 
himbauan dari pihak terkait dalam mengantisipasi bencana, kurangnya kesiapsiagaan SMP Muhammadiyah 7 Bayat diperkuat dengan hasil persentase tingginya siswa yang memiliki kesiapsiagaan rendah yaitu $52 \%$. Hal ini menjadi indikator SMP Muhammadyah 7 Bayat memiliki tingkat kesiapsiagaan terhadap bencana dalam kategori rendah.

Tingkat kesiapsiagaan di MBS Prambanan sudah cukup baik dengan tingkat persentase 64\% (Gambar 8). Hal ini dipengaruhi dari adanya faktor intern dan ekstern yang berperan meningkatkan kesiapsiagaan siswa dalam menghadapi bencana, sekaligus menekan tingkat persentase rendahnya tingkat pengetahuan siswa terhadap bencana yaitu $36 \%$. Hal ini menjadikan MBS Prambanan diyakini mampu dan cukup siap dalam menghadapi bencana dengan tingkat kesiapsiagaan 64\% berbanding 36\%.

Menurut Abdurrahman (2011), menjelaskan bahwa upaya sosialisasi kebencanaan akan sangat efektif bila dilaksanakan melalui persekolahan. Setiap tahun ajaran akan datang siswa baru, dan merekalah yang akan menjadi penyampai tentang mitigasi bencana.

\section{Respon Siswa Terhadap Gempa Bumi Disekolah}

Respon siswa terhadap gempa bumi disekolah merupakan hasil akhir dari pengalaman, pemahaman, kesiapsiagaan siswa terhadap bencana baik tidaknya dilihat dari respon siswa saat menghadapi bencana. Menurut Hidayati (2006), mengemukakan bahwa manajemen bencana yang seringkali hanya sebatas respon-respon reaktif jangka pendek dan kurang berorientasi pada tindakan proaktif. Kesiapsiagaan serta upaya mitigasi jangka panjang dapat mengakibatkan kesiapsiagaan terus menurun. Respon siswa terhadap bencana gempa bumi di sekolah khusunya di SMP 7 Bayat dan MBS Prambanan dalam menghadapi ancaman gempa bumi di daerah Kabupaten Klaten disajikan pada Gambar 9 dan 10.
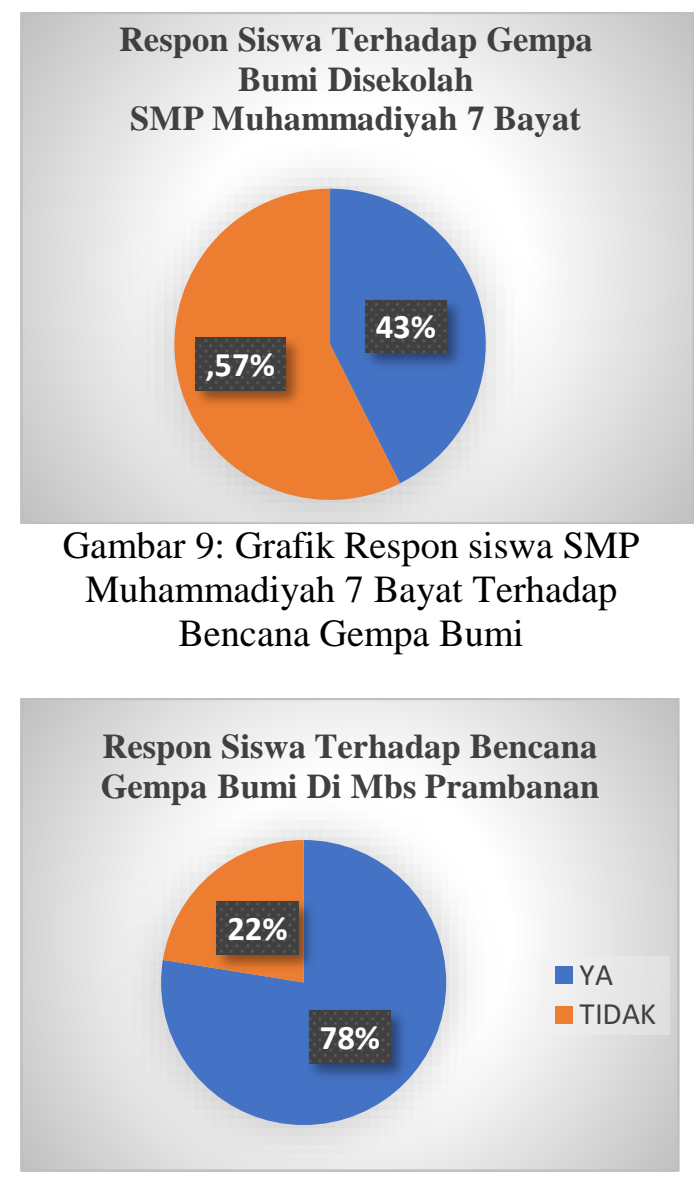

Gambar 10: Grafik Respon siswa SMP MBS Prambanan Terhadap Bencana Gempa Bumi

Resepon siswa terhadap gempa bumi di SMP Muhammadiyah 7 Bayat diperoleh hasil dengan presentase yang kurang baik dalam merespon bencana gempa bumi yaitu sebesar $43 \%$ siswa mampu merespon bencana gempa bumi dan sebesar $57 \%$ siswa memiliki tingkat respon rendah terhadap bencana gempa bumi (Gambar 9). Hal ini dapat di simpulkan kapasitas siswa SMP Muhammadyah 7 Bayat 
dikategorikan rendah dengan tingkat kerentanan yang cukup tinggi. Hal ini sangatlah beresiko jika tidak cepat ditangani dengan adanya sosialisasi, simulasi dan penyampaian materi kebencanaan secara berkala dengan harapan meningkatnya kapasitas siswa dalam merespon bencana gempabumi.

Berbada dengan respon siswa terhadap gempa bumi di MBS Prambanan yang memiliki persentase sangat baik yaitu $78 \%$ siswa memiliki kemampuan merespon bencana gempa bumi, dan $22 \%$ siswa yang memiliki kemampuan kurang dalam merespon bencana gempa bumi (Gambar 10). Berdasarkan hal tersebut, siswa MBS Prambanan sudah memiliki kapasitas yang cukup dalam merespon bencana gempa bumi di sekolah dengan tingkat kerentanan yang rendah. Hal ini sebanding dengan adanya sosialisasi secara terus menerus dan adanya pelatihan kebencanaan dari berbagai pihak intern maupun ekstern dalam kegiatan penelitian sehingga secara tidak langsung memberikan pengetahuan dan pengalaman kebencanaan pada siswa (Syuaib 2013).

\section{Pemahaman Siswa Terhadap Mitigasi Bencana Gempa Bumi}

Pemahaman siswa terhadap mitigasi bencana gempa bumi merupakan persiapan awal siswa dalam bermitigasi pra-bencana untuk kemudian di aplikasikan dalam respon siswa terhadap bencana maka siswa harus memiliki pemahaman yang cukup dalam bermitigasi (Husnul 2015). Pemahaman siswa terhadap mitigasi bencana gempa bumi khusunya di SMP 7 Bayat dan MBS Prambanan tentang bencana siswa dalam menghadapi ancaman gempa bumi di daerah Kabupaten Klaten disajikan pada Gambar 11 dan 12.

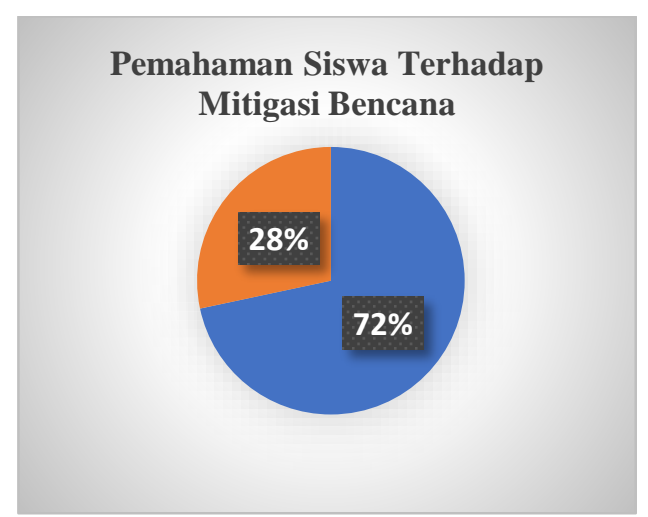

Gambar 11: Grafik Pemahaman siswa SMP Muhammadiyah 7 Bayat Terhadap Mitigasi Bencana

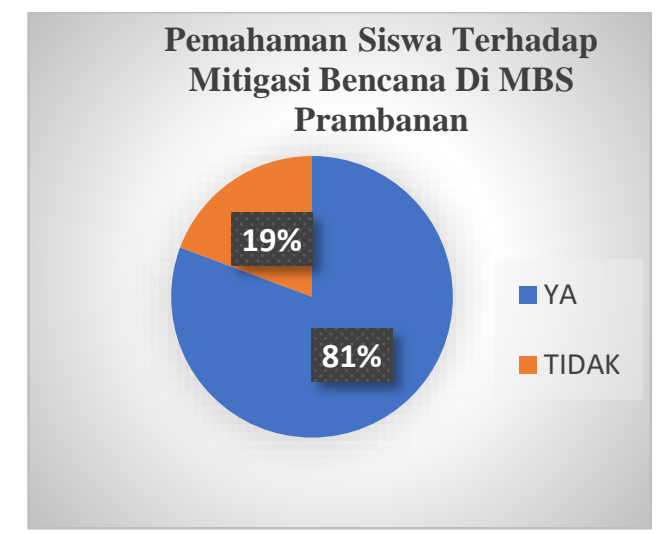

Gambar 12: Grafik Pemahaman siswa SMP MBS Prambanan Terhadap Mitigasi Bencana

\section{Berdasarkan Gambar 11 SMP} Muhammadyah 7 Bayat tercatat tingkat pemahaman siswa yang baik terhadap mitigasi bencana gempa bumi yaitu $72 \%$, dan siswa yang memiliki tingkat pemhaman kurang terhadap mitigasi bencana sejumlah $28 \%$. Hal ini menjadikan SMP Muhammadiyah 7 Bayat memiliki tingkat pemahaman yang cukup dalam bemitigasi bencana bencana gempa bumi, sehingga tingkat kerentanan cukup rendah guna mengurangi risiko bencana.

Pemahaman siswa terhadap mitigasi bencana di MBS Prambanan sangat baik. hal ini dapat dilihat dari hasil grafik yang menggambarkan tingginya pemahaman siswa MBS Prambanan sebesar $81 \%$, dan hanya $19 \%$ siswa yang kurang paham 
bermitigasi bencana. Beradasarkan hal itu, dapat di indikasikan siswa MBS Prambanan sudah siap dalam menghadapi bencana gempa bumi hal ini dibuktikan dari data tingginya pengetahuan siswa dalam bermitigasi sehingga dapat menekan tingginya tingkat kerentanan dan risiko bencana.

\section{Respon Siswa Terhadap Bencana}

Hasil keseluruhan merupakan akumulasi dari grafik sebelumnya guna menentukan kualitas, kapasitas, kerentanan, tingkat risiko suatu sekolah dalam menghadapi bencana berdasarkan pengalaman siswa, pengetahuan siswa, kesiapsiagaan siswa, respo siswa dan pemahaman siswa dalam bemitigasi gempa bumi. Hasil analisis respon siswa di SMP 7 Bayat dan MBS Prambanan adapun dalam menghadapi ancaman gempa bumi di daerah Kabupaten Klaten disajikan pada Gambar 13 dan 14.

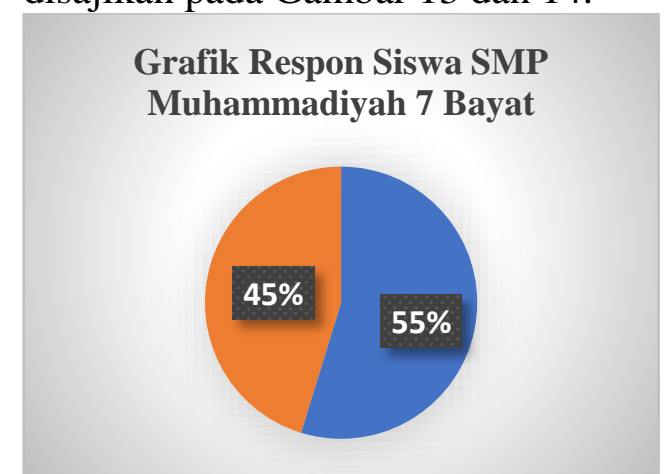

Gambar 13: Grafik Respon Siswa terhadap bencana

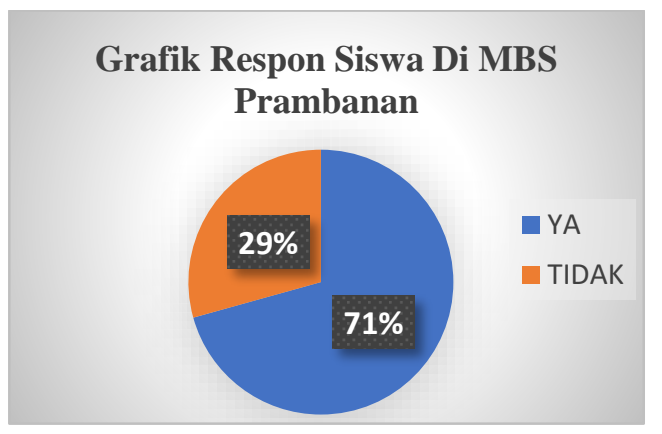

Gambar 13: Grafik Respon Siswa terhadap bencana
Berdasarkan keseluruhan data grafik SMP Muhammadiyah 7 Bayat diperoleh hasil $55 \%$ siswa mamiliki kapasitas yang cukup dalam menghadapi bencana gempa bumi. Data tersebut merupakan akumulasi dari pengalaman siswa, pengetahuan siswa, kesiapsiagaan siswa, respon siswa dan pemahaman siswa dalam bemitigasi gempa bumi. Selain itu, terdapat $45 \%$, siswa dengan kategori cukup mampu dalam merespon adanya bencana gempa bumi. Akan tetapi, perlu adanya peningkatan dan usaha lebih dalam menambah kapasitas kemampuan siswa dalam hal kebencanaan guna mengurangi risiko bencana dan meminimalisir korban dan kerusakan (Gambar 13).

Berdasarkan grafik keseluruhan di MBS Prambanan di peroleh hasil yang sangat signifikan yaitu sebesar $71 \%$ siswa siap menghadapi bencana khususnya gempa bumi dengan kategori baik sehingga dapat di simpulkan kapasitas siswa tergolong tinggi. Meskipun terdapat 29\% pemahaman siswa yang belum maksimum dalam bemitigasi gempa bumi. Hal ini tidak lepas dari adanya peran sekolah dan eksternal sekolah yang giat memberi penyuluhan guna meningkatkan kualitas dan kapasitas siswa dalam bidang kebencanaan.

\section{KESIMPULAN}

Dari hasil penelitian dapat disimpulkan bahwa tingkat pengetahuan warga SMP Muhammadyah 7 Bayat termasuk dalam kategori sedang, hal ini dipengaruhi oleh sumber dan media informasi, media pengajaran dan sosialisasi tentang kebencanaan yang kurang guna meningkatkan pengetahuan warga SMP Muhammadiyah 7 Bayat, sedangkan tingkat pengetahuan warga SMP MBS 
2 Prambanan termasuk dalam kategori tinggi. hal ini dipengaruhi oleh sumber dan media informasi, media pengajaran dan sosialisasi tentang kebencanaan yang rutin dilakukan sehingga tingkat pengetahuan warga SMP MBS 2 Prambanan sangat tinggi.

$\begin{array}{rrr}\text { Berdasarkan data } & \text { yang } \\ \text { diperoleh respon warga } & \text { SMP }\end{array}$ Muhammadiyah 7 Bayat terhadap bencana gempa bumi masuk dalam kategori kurang hal ini dipengaruhi oleh tingkat pengalaman, pengetahuan, kesiap siagaan tentang bencana yang rendah dikarenakan kurangnya pengajaran tentang bermitigasi bencana, sedangkan respon SMP MBS 2 Prambanan terhadap bencana gempa bumi masuk dalam kategori tinggi. Hal ini dipengaruhi oleh tingkat pengalaman, pengetahuan, kesiap siagaan tentang bencana yang tinggi hasil penerapan pendidikan kebencanaan.

\section{DAFTAR PUSTAKA}

Ardiansyah, Agustian Deny. (2017). Kesiapsiagaan Guru SMAN 1 Prambanan Dalam Menghadapi Bencana Gempa Bumi. Jurnal Pendidikan Geografi: Kajian, Teori, dan Praktek dalam Bidang Pendidikan dan Ilmu Geografi. 22 (2), Hal 121-134.

Badan Penanggulangan Bencana Daerah. 2014. Panduan Pembelajaran Kebencanaan di Kabupaten Klaten. Klaten.

Chairummi, Sari, A.S., \& Ridha, M. (2013). Pengaruh Konsep Diri dan Pengetahuan Siswa Terhadap Kesiapsiagaan Bencana Gempabumi di SDN 27 dan MIN Merduati Banda Aceh. Kesehatan Ilmiah
Nasuwakes. 6 (2). hlm:239249.

Deny Hidayati. (2006). Kajian Kesiapsiagaan Masyarakat Dalam Mengantisipasi Bencana Gempa Bumi dan Tsunami. Jakarta: LIPI Press.

Dewi, Anggraeny Kusuma. (2014). Kapasitas Masyarakat Sekitar ITB dalam Menghadapi Gempa Bumi. Jurnal Dialog Pengangulangan Bencana, 5(1). Hal 11-24.

Hidayati, Eri. (2016). Pendidikan Kesiapsiagaan Bencana Gempa Bumi dan Tsunami Dengan Metode PlayTherapy Melalui Pusijump (Puzzle, Music, and MagicJump) Untuk Siswa Tunagrahita.

Jufriadi, Akhmad. (2012). Sosialisasi "Pengurangan Resiko Bencana" di Kecamatan Tempursari Kabupaten Lumajang Sebagai Upaya Pendidikan Mitigasi Bencana. ERUDIO. Vol. 1(1).

Khatimah, Husnul. (2015). Pengaruh Penerapan Metode Simulasi SchoolWatching Terhadap Sikap Kesiapsiagaan Siswa Dalam Menghadapi Bencana Gempa Bumi. Jurnal Ilmu Kebencanaan. Vol. 2(1). Hal 11-18.

Lenni Kartika I., B. Triatmodjo, Radianta T. 2008. Evaluasi Sistim MitigasiPenangnan Bencana Gempa Bumi Di Kecamatan Bantul Provinsi Daerah Istimewa Yogyakarta. Forum Teknik Sipil. No. XVIII/3. 
49 | Jurnal Geografi, Edukasi dan Lingkungan (JGEL) Vol. 4, No. 1, Januari 2020:39-49

Oman, Abdurahman. (2011) Hidup Di Atas Tiga Lempeng. Bandung: Badan Geologi.

Pasau, Guntur. (2011). ReaponsSepektra Gempa Bumi Di Batuan Dasar Kota Bitung Sulawesi Utara Pada Periode Ulang 2500 Tahun. Jurnal Ilmiah Sains. Vol. 11 No. 1.

Siregar, S. (2013). Metode Penelitian Kuantitatif Dilengkapi Perbandingan Perhitungan Manual \& SPSS. Jakarta: Kencana Prenadamedia Group.

Sugiyono. (2007). Metode Penelitian Kuantitaif, Kualitatif dan $R$ $\& D$. Bandung. Alfabeta

Syuaib, M. Z. (2013). Pengaruh Strategi Pembelajaran Simulasi Vs Bermain Peran dan Sikap Siswa Terhadap Pengetahuan Dan Kesiapsiagaan Tentang Bencana Alam. Jurnal Pendidikan Humaniora.1 (2). hlm:177-189. 